Association for Information Systems AIS Electronic Library (AISeL)

$12-13-2018$

\title{
Perceptions of Web Accessibility Guidelines by Student Website and App Developers
}

Shiya Cao

Worcester Polytechnic Institute, scao2@wpi.edu

Eleanor Loiacono

Worcester Polytechnic Institute, eloiacon@wpi.edu

Follow this and additional works at: https://aisel.aisnet.org/sighci2018

\section{Recommended Citation}

Cao, Shiya and Loiacono, Eleanor, "Perceptions of Web Accessibility Guidelines by Student Website and App Developers" (2018). SIGHCI 2018 Proceedings. 17.

https://aisel.aisnet.org/sighci2018/17

This material is brought to you by the Special Interest Group on Human-Computer Interaction at AIS Electronic Library (AISeL). It has been accepted for inclusion in SIGHCI 2018 Proceedings by an authorized administrator of AIS Electronic Library (AISeL). For more information, please contact elibrary@aisnet.org. 


\section{Perceptions of Web Accessibility Guidelines by Student Website and App Developers}

\author{
Shiya Cao \\ Worcester Polytechnic Institute \\ scao2@wpi.edu
}

\author{
Eleanor Loiacono \\ Worcester Polytechnic Institute \\ eloiacon@wpi.edu
}

\begin{abstract}
Websites and applications (apps) have become an essential part of daily life. However, pervious research has shown that many people have trouble experiencing websites and apps fully due to accessibility issues. One of the reasons often cited for inaccessible websites and apps is related to training, or a lack thereof. Many developers are not educated, or even exposed, to Web accessibility guidelines. Thus, understanding the extent to which student website and app developers are exposed to accessibility in their college courses is a critical first step in determining how to increase their use of accessibility guidelines. This mixed methods research in progress aims to better understand the influence of education and training on the perceptions of Web accessibility guidelines by student website and app developers. This research promises theoretical and practical contributions with regard to student website and app developers.
\end{abstract}

\section{Keywords}

Web accessibility, accessibility guidelines, student website and app developers, education and training.

\section{INTRODUCTION}

World Wide Web Consortium (W3C) Accessibility Guidelines have existed for a number of years to ensure people with disabilities have access to information on websites and in applications (apps). For example, one recommendation contained in the newly released Web Content Accessibility Guidelines (WCAG) (version 2.1, released June 5, 2018) is to "provide text alternatives for any non-text content so that it can be changed into other forms people need, such as large print, braille, speech, symbols or simpler language" (https://www.w3.org/TR/2018/REC-WCAG21-

20180605/). This ensures that people with different disabilities, such as deafness or blindness, can still gain access to the online material. However, research shows that websites and apps continue to be inaccessible (Loiacono 2004; Loiacono et al. 2005; Loiacono et al. 2009). The Business Disability Forum has been assessing the accessibility of websites since 2008 and in that time $70 \%$ of the reviewed websites were assessed as lacking accessibility (Rocca 2016). Another assessment (Castro et al. 2017) conducted by Information Technology \& Innovation Foundation (ITIF) in 2016 and 2017, indicated that $42 \%$ of the 260 most popular federal government websites in the U.S.A. failed the accessibility test for people with disabilities.

One of the reasons often cited for inaccessible websites and apps is related to training, or a lack thereof. Many developers are not educated on, or even exposed to accessibility guidelines in their college preparation. Thus, a critical first step is to understand the extent to which student website and app developers are currently exposed to accessibility in their college courses and to investigate whether or not these courses impact the perceptions of Web accessibility guidelines by student website and app developers. To do this, we focus on the following research questions:

(1) How familiar are student website and app developers with accessibility guidelines?

(2) Is education and training helpful to improve perceptions of Web accessibility guidelines by student website and app developers?

This research is a continuation of an undergraduate students' project, in which three undergraduate students collected quantitative and qualitative data at a university from September 2017 to December 2017. Further data collection is ongoing, and the participant pool has been expanded, to include students from various universities in the Northeastern US. The findings from the quantitative and qualitative data will provide deep insight into the perceptions of Web accessibility guidelines by student website and app developers.

\section{LITERATURE REVIEW}

Previous research (Lawton et al. 2005; Lawton 2017) indicated that Web accessibility is not only crucial for people with disabilities but can also be important for people without disabilities. Web accessibility guidelines are a key resource to design and develop accessible websites and apps (Loiacono 2004; Rouse 2010). Research has even shown that legislation can compel companies to increase their adherence to accessibility guidelines (Loiacono 2011). Pervious research (Lazar et al. 2004; Abou-Zahra 2017) showed that education, training, and 
awareness of diverse disabilities help enhance the understanding of Web accessibility.

\section{Web Accessibility Is Beneficial to Everyone}

It is paramount that websites and apps be usable by all people across different situations. Even though a large portion of the population is able to access websites and apps without much trouble, there is also a large group of people who require additional tools or enhancements in order to use websites and apps. This includes people with temporary or changing disabilities and means that everyone must be able to perceive, understand, navigate and contribute to websites and apps (Lawton et al. 2005). It is also the socially responsible thing to do (Lawton et al. $2005)$; it is a human right for everyone to have equal access and equal opportunity (Lawton 2017). Websites and apps support social inclusion on a local and global level; people from any background or situation can contribute to a worldwide online community. Accessible websites and apps can also hugely benefit companies. A website or app that is well designed and accessible provides better searchengine optimization (SEO) and usually requires less maintenance (Lawton, 2017). Inaccessible websites and apps hinder usage for people with disabilities while also being inconvenient to people without disabilities. For instance, under the WCAG, ensuring that there are definitions for idioms, jargon, or abbreviations used on websites and apps, can not only help those with cognitive issues, but also those unfamiliar with the topic of the website or app. Therefore, Web accessibility can benefit everyone.

Web Accessibility Guidelines Are Essential to Design Accessible Web

The W3C founded the Web Accessibility Initiative (WAI) in 1996. The WAI has developed guidelines for creating accessible website pages. The initial WCAG version 1.0 was developed in 1999 and the WAI updated WCAG version 2.1 in 2018. This new version includes four guiding principles and 13 guidelines to ensure website page content such as text, images, forms, and sounds accessible to people with disabilities (https://www.w3.org/TR/WCAG21/\#conformance). The four guiding principles regulate that websites must be perceivable, operable, understandable, and robust. Additionally, the United States government provides guidelines and tools in the Section 508 initiative (https://www.section508.gov/), requiring that all electronic and information technology must be accessible to people with disabilities (Rouse, 2010). Another example, the Americans with Disabilities Act (ADA), which was passed by the United States Congress in 1990, has been expanded to cover the accessibility of websites, requiring that websites must be prepared to offer those communications through accessible means (Kaplan 2000).

Awareness of Diverse Disabilities Helps People Understand Various Demands of Web Accessibility
People with different types of disabilities need different accessibility features. For example, those with speech disabilities require an alternative to voice-based software services, while those with cognitive disabilities can be assisted by websites that are clearly structured. Even people with the same category of disability may require different demands depending on the degree of their disability. For instance, for those who are just hard of hearing, good audio quality and the ability to change the volume of media is an acceptable starting point; however, for those who are completely deaf, an alternative to audio is necessary-- usually addressed by using captions for videos or by supplying a separate transcript (Abou-Zahra 2017).

\section{Education and Training Help Form the Perceptions of Web Accessibility}

Lazar et al. (2004) found that societal foundations, such as education and training, influence website and app developers on their awareness and decision of whether a website or app will be built for accessibility or not. Education and training play an important role in the perceptions of Web accessibility, especially for student website and app developers because they acquire knowledge mainly from the classroom and related projects.

\section{THEORETICAL FRAMEWORK}

The Technology Acceptance Model (TAM), introduced by Fred Davis (1989), has become a paradigm in the Information Systems (IS) discipline. One of the key contributions of TAM is to provide a theoretical foundation for tracing the influence of external variables on perceived usefulness and perceived ease of use, attitude toward using, behavioral intention to use, until actual system use (Davis et al. 1989). For example, a program provided to potential users that educates about the usefulness of a given system and the degree to which it may improve users' performance could have a big impact on attitude toward system use (Davis et al. 1989).

In this study, we focus on the first part of TAM--the influence of external variables to perceived usefulness and perceived ease of use. We interpret it as the role of education and training in shaping the perceptions of Web accessibility by student website and app developers. Education and training, which refers to college-level website and app development or design courses that discuss accessibility, may help student website and app developers aware of people with diverse disabilities and their different demands for the Web, exposed to the concept of Web accessibility, and familiar with accessibility guidelines to implement accessible features. Specifically, awareness of diverse disabilities is related to usefulness beliefs of Web accessibility because knowing of diverse disabilities will help understand different accessibility features, and vice versa (Abou-Zahra 2017). Exposure to accessibility is defined as the extent to which students are exposed to the concept of Web accessibility. Familiarity with accessibility guidelines is to investigate 
students' familiarity with three main accessibility guidelines and laws in the US, including WCAG, Section 508, and ADA. If a student is not aware of and/or familiar with a technology, he or she will have little perception of usefulness and ease of use of this technology and thus it seems less likely that he or she will be willing to use the technology.

Different from TAM, we plan to work backwards on the external variable-education and training, and the perceptions of Web accessibility by student website and app developers. In doing this, we will predict whether or not students have been educated about accessibility based on their awareness of diverse disabilities, exposure to accessibility, and familiarity of accessibility guidelines. The logic behind this is if we can accurately predict education and training from the predictor variables, it means there is some significant difference between student website and app developers who have been trained and those who have been not. Therefore, it can test one of our research questions: Is education and training helpful to improve perceptions of Web accessibility guidelines by student website and app developers? Based on the above analysis, we present the theoretical framework of this research as shown in Figure 1.

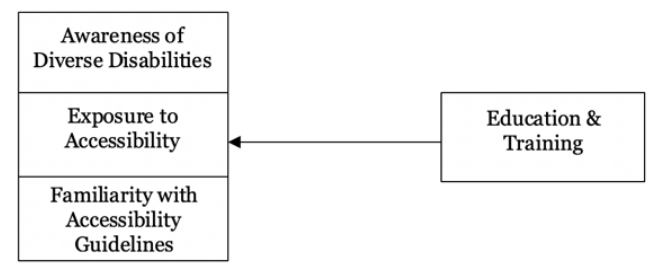

Figure 1. Theoretical Framework

We hypothesize:

H1: Students, who have a higher reported level of awareness of diverse disabilities, exposure to accessibility, and familiarity with accessibility guidelines, are more likely to have taken courses that discuss accessibility than those who have a lower reported level of these variables.

\section{METHODOLOGY}

This research uses a mixed methods design to investigate our research questions. We have collected the quantitative and qualitative data ${ }^{1}$, analyzed the quantitative data, and explained the quantitative results with in-depth qualitative data. The reason for collecting both quantitative and qualitative data is to provide a comprehensive and deep understanding of the perceptions of Web accessibility guidelines by student website and app developers.

\section{Quantitative Data}

1 Three undergraduate students collected part of the quantitative and qualitative data in their Interactive
The survey questionnaire, consisting of 15 questions, was developed by the researchers and reviewed by experts in website and app development and accessibility. Except for the demographic questions, all questions focus on student website and app developers' experiences and perceptions of Web accessibility guidelines. These questions contain various types of questions, including multiple choice and open-ended questions. The questionnaire was pilot tested by researchers and random subjects (not include in the survey data). Institutional Review Board (IRB) approval was obtained for the study (both survey and interview protocol). Advertisements to faculty who teach website and app development or design courses in various universities in the Northeastern US. Faculty who were willing to promote this research sent the study promotion email and survey link to their students. Using this approach, we make sure that participants have a background knowledge of Web accessibility. Survey data continues to be collected. Participants were solicited through Qualtrics.

\section{Qualitative Data}

To enhance our understanding of the quantitative data, at the end of the survey questionnaire, we ask participants if they are willing to sign up for interviews or not. If they are willing to participate in interviews, they will click a link provided in the questionnaire, which leads to a time-slot sheet for signing up for interviews by Slottr. Signing up for a time-slot requires the participant's email. Then researchers will contact participants through email to check interview dates and times and send participants the consent form approved by IRB. An approved protocol, which was also reviewed by the experts, is being used to conduct the interview. The interview consisted of 14 questions. Overall, the interviews were about respondents' experiences and perceptions of accessibility guidelines. In addition, some questions delved into respondents' experiences in implementing Web accessibility in their work. Interviews lasted around 15 minutes. For those who agreed to it, interviews were audio recorded and transcribed to ensure accuracy of notetaking. Participants who finished both survey and interview were awarded $\$ 5$ Amazon gift cards.

\section{Demographics of Participants}

As of today, we have collected a total of 76 surveys and 34 interviews. The number of participants in each gender was 54 in male $(71.1 \%), 20$ in female $(26.3 \%), 1$ in other identification $(1.3 \%)$, and 1 in preferred not to answer $(1.3 \%)$. The sample consisted of 56 undergraduate students $(73.7 \%)$ and 20 graduate students $(26.3 \%)$. The number of participants in each major was 36 in computer science $(47.4 \%), 21$ in information technology $(27.6 \%), 17$ in other majors $(22.4 \%)$, and 2 students did not state their majors $(2.6 \%)$. The interview sample consisted of 23 male $(67.6 \%)$ and 11 female (32.4\%), 24 undergraduate students

Qualifying Project (IQP) from September 2017 to December 2017. 
(70.6\%) and 10 graduate students (29.4\%), as well as 18 in computer science $(52.9 \%), 6$ in information technology $(17.6 \%)$, and 10 in other majors $(29.4 \%)$.

\section{Data Analysis Plan}

To predict whether or not students who have been educated about accessibility based on their awareness of diverse disabilities, exposure to accessibility, and familiarity of accessibility guidelines, we will use binary logistic regression models to analyze the data. Logistic regression analysis can be used to test whether or not there is a causal link between independent variables and the dependent variable. The regression analysis will be conducted by the Statistical Package for the Social Sciences (SPSS). We will also conduct a receiver operating characteristic (ROC) analysis in order to assess the accuracy of the decision strategy to predict education about accessibility. After the quantitative data analysis, we will use NVivo to analyze the qualitative data in order to deeply explore the quantitative results.

\section{POTENTIAL CONTRIBUTIONS AND LIMITATIONS}

This research will have both theoretical and practical contributions. Theoretically, this work is going to enrich the information systems' literature about the role of education and training in the perceptions of Web accessibility guidelines. Moreover, it will delve deep into the formation of perceptions towards accessibility guidelines. Practically, this study will inform institutions, instructors, training organizations, and website and app development or design companies about the role of education and training in the perceptions of accessibility guidelines.

This research is a critical first step to understand the extent to which current student website and app developers are exposed to accessibility in their college courses and the influence of these courses on their perceptions of accessibility guidelines. However, we want to have a broader view in future research. First, we want to extend our research model in order to investigate the impact of education and training on actual application of accessibility guidelines in students' website and app designs. Second, we want to expand the range of student participants in order to increase the generalizability of the results of this study.

\section{REFERENCES}

1. Abou-Zahra, S. 2017. "Diversity Of Web Users," https://www.w3.org/WAI/intro/people-useweb/diversity

2. Caldwell, B., et. al. 2008. "Web Content Accessibility Guidelines 2.0," https://www.w3.org/TR/WCAG20.
3. Castro, D., Nurko, G., McQuinn A. 2017. "Benchmarking U.S. Government Websites," Information Technology \& Innovation Foundation, pp. 60 .

4. Davis, F. 1989. "Perceived usefulness, perceived ease of use, and user acceptance of information technology", MIS Quarterly (13:3), pp. 319-339.

5. Davis, F., Bagozzi, R., Warshaw, P. 1989. "User acceptance of computer technology: A comparison of two theoretical models," Management Science (35), pp. 982-1003.

6. Kaplan, F. M. 2000. "Designing a Web site that is ADA-compliant,” NREI, pp. 34.

7. Lazar, J., Dudley-Sponaugle A., Greenidge K. 2004. "Improving web accessibility: a study of webmaster perceptions," Computers in Human Behavior (20), pp. 269-288.

8. Lawton, H. 2005. "Essential Components Of Web Accessibility," https://www.w3.org/WAI/intro/components.php

9. Lawton, H., Liam, M. 2017. "Web Design And Accessibility," https://www.w3.org/standards/webdesign/accessibilit $\mathrm{y}$

10. Loiacono, E. 2004. "Cyberaccess: Web Accessibility and Corporate America," Communications of the ACM (47), pp. 83-87.

11. Loiacono, E., Djamasbi, S. 2011. “Corporate Website Accessibility: Does Legislation Matter?" Universal Access in the Information Society, pp. 1-10.

12. Loiacono, E., McCoy, S. 2005. "Website Accessibility: A Cross-Sector Comparison," The Universal Access in the Information Society (4), pp. 393-399.

13. Loiacono, E., Romano, N., McCoy, S. 2009. "The State of Corporate Website Accessibility," Communications of the ACM (52), pp. 128-132.

14. Rocca, D. 2016. "Seventy Percent of Websites Are Breaking the Law on Accessibility - Here's How and Why That Needs to Change," https://www.huffingtonpost.co.uk/damiano-larocca/websiteaccessibility_b_9931304.html?guccounter=1\&guce_r eferrer_us $=\mathrm{aH} \overline{\mathrm{R}} 0 \mathrm{cHM} 6 \mathrm{Ly} 93 \mathrm{~d} 3 \mathrm{cuZ29} \mathrm{vZ2x1LmNvb \overline {S }}$ 8\&guce_referrer_cs $=$ san1gOKPPficWO8ejmeEZg

15. Rouse, M. 2010. "Section 508," https://searchcio.techtarget.com/definition/Section$\underline{508}$ 